\title{
eParticipation Issues in Contemporary Europe
}

\author{
Rada Cristina Irimie \\ Babeş-Bolyai University, Cluj-Napoca, Romania \\ radairimie@yahoo.com
}

\begin{abstract}
:
Today, Information and Communication Technologies have developed to the extent of amplifying political procedures that are central to the contemporary civic society, such as political participation and citizen engagement. eParticipation is a multidisciplinary field of study, which is particularly relevant in several contexts and environments, e.g. digital democracy, public services, open government, popular social media etc. This paper addresses the eParticipation framework in the European context, during the last 10 years. Our research will explore theoretically and empirically how citizen participation is achieved through social media and digital public services. The article explores both the cultural and political environments that favor the development of eParticipation initiatives, with the study of networking interactions based on social and public policy initiatives. We are particularly interested in the public policy formulations that embrace eParticipation and most importantly the recent developments in the field, which include a number of eConsultation, ePolling, eLegislation, eElectioneering, eVoting etc. A review of the good practice examples in eParticipation policy development will help us identify the strengths and weaknesses of the digital framework. Within the context of social value, we want to explore the aspect of eParticipation in the broader political scene, by examining the role of digital participation in political crises. By drawing examples based on case studies of public policy formulation in European countries, the research suggests a correlation between digital innovation and challenging politics. The framework is originally designed to be sustainable for the European societies and it places citizens in the center of its conception. It is, however, argued that the interaction between public policy innovation and citizen engagement needs continuous scholarly attention and study.
\end{abstract}

Keywords: eParticipation, innovation, eGovernment, social media, citizen engagement

\section{Introduction}

The potential for Information and Communication Technologies (ICTs) to increase political participation and address the growing democratic deficit across Europe and elsewhere has been the subject of many discussions. However, only recently a sufficient application of ICTs for the support of democracy has put this 'potential' in a real-world context. Past scholar work (Macintosh et al, 2003) considered two components to eDemocracy, one including eVoting as a part of the electoral process, and the other including eParticipation as a part of democratic decision-making. This article concerns the use of Information and Communication Technologies as a process that reinforces democratic participation and focuses on the value and use of ICTs in participatory democracy, while special attention is paid with regards to European democracies. The review of the eParticipationpractice aims to clarify some possible prospects and limitations offered by ICTs in the participatory process. An important part of research on digital democracy in the last decade highlights the political advantages deriving from the use of the internet (Delli-Carpini, 2000; Coleman \& Gøtze, 2004; Stanley \& Weare, 2004). Given that citizen participation in technological resources is becoming increasingly common in Europe, learning from the recent experiences should be of particular interest to scholars and practitioners working in the field of eParticipation. The article builds on these earlier relevant studies and uses the definition of eParticipation as the use of ICTs to support information provision and 'top-down' engagement or 'ground-up' efforts to empower citizens, civil society organisations and other democratically constituted groups in order to gain the support of their elected representatives. Effective information provision is often seen as the conclusion of effective engagement and empowerment (Macintosh \& Whyte, 2008).

As eParticipation applications gradually multiply both in the European Union and internationally, new systemic challenges emerge. Design of evolved services, new political initiatives and technological developments have to be examined under the light of a maturing domain. Within this context, the article will bring together a review of programs that are currently being implemented with the theoretical base founded upon, in order to discuss issues of both ideological and practical nature, so that a real exchange of knowledge and experience can be achieved. Specific attention will be paid, apart from 
policy and technology issues, to implementation-related issues, such as good practice examples. Among other findings, this paper discusses the political value of the initiative for the contemporary European societies, as well as its role in political crisis. It is expected that the outcome of this research will contribute to the literature on electronic and participatory democracy, as well as provide a policy evaluation of the use of ICTs in a large-scale participatory initiative. The article will highlight four main challenges for eParticipation. The first will focus on the dual perspective; from the citizen's point of view how can technology enable an individual's voice to be heard and not be lost in the mass debate? There is a great need for technology and supporting measures to enable virtual public spaces such that an individual's voice develops into a community voice. From a government's perspective, there is the challenge of how to listen to and respond to each individual. Fostering online communities and developing e-engagement tools to support such communities could enable a more collective approach. The second challenge is how to build capacity and active citizenship by controlling ICTs power to encourage involvement of more citizens on public issues. This creates the requirement for accessible and comprehensible information and the opportunity to debate on important social issues. The third challenge concerns coherence. New information and communication technologies can be used to support the information, consultation, participation and analysis, as well as evaluation. Finally, consideration should be given to knowledge management methods and approaches so that they can support policy-making. It is expected that the outcome of this research will contribute to the literature on electronic and participatory democracy, as well as provide a policy evaluation of the use of ICTs in a large-scale participatory initiative.

\section{Understanding eParticipation}

Online political participation is a challenging topic and object of research. In the literature, it is frequently found under eDemocracy, since both eParticipation and eDemocracy are conceptional compounds of the use of Information and Communication Technologies that link citizens with one another and with their elected government (Gadras \& Geffet, 2013). This normative assumption is based on the conception of digital technologies that is supported by political actors and interest groups promoting eDemocracy. In this perspective, technologies are concerned to be a modern way to the reinvention of political networking and re-establishment of citizen-centred systems (Rosanvallon, 2008). The 'digital agenda for Europe', the initiative of the European Commission as a part of the Europe 2020 programme, reflects and puts these concerns into perspective and terms of public policies (Chrisaffis \& Rohen, 2010). The phenomenon of eParticipation has received increased attention during the last ten years, due to late technological advancements, experiments, policy reports and research implementations. Understanding this emerging field of politics is not easy as there is no approved definition of the field, no specific overview of the research disciplines or methods and because the boundaries of the field are undecided (Sæbø et al, 2008). Traditional literature will help us to identify scientific considerations important for the field's theoretical development. The theories used for this chapter provide the starting point for a grounded analysis that leads to the deployment of a general model: the eParticipation seen from a researcher's point of view. The theories provide structure for understanding the developing field, as well as an initial suggestion of its content. It also provides the basis for developing research guides for the future. eParticipation involves a technology-based interaction between citizens and the political sphere and between citizens and administration (Porwol, 2013).

The utilisation of information and communication technology in political participation enables public participation and interactiveness through simultaneous feedback and opens up a new channel for political participation while strengthening existing citizen engagement (Dijk, 2000). These notions of eParticipation as a consultative, democratic process which involves citizens in policy-making does not consider communication among citizens on informal channels such as social media. This chapter is a first step towards the understanding of citizen-focused eParticipation. We aim to develop an analytical framework for the understanding of government and citizen-led eParticipation; defining the conditions under which the integration of the two types of eParticipation produce the best outcome; and determining the potential of government and citizens to embrace eParticipation. To attempt a first approach of the concept of eParticipation, we need to analyse the term: 'e' and 'participation'. Participation is generally understood as 'joining' in the sense of taking part in some communal form of action, or in the sense of undertaking a role in decision-making (Sæbø et al, 2008). Though participation is the subject of many theoretical discussions (e.g. participatory management, community participation, participatory research), eParticipation is usually associated with some form of political initiative or decision-making. Participation is an integral part of the democratic political system (e.g. voting or activism). This literature research focuses on political participation in the decision-making sense and covers participation within and outside the formal political system. The 'e(lectronic)' in eParticipation has a direct association with recent 'e' disciplines (e.g. eBusiness, eGovernment) and 
refers to the leverage of information and communication technologies (mainly, the internet) for the transformation of citizen involvement in decision-making processes.

eParticipation is largely understood as the technology-moderated interaction between the social and political spheres and between civil society and administration (Porwol, 2013). The focal point of eParticipation is the citizen, i.e., the target of eParticipation is to increase citizens' participatory power through digital governance. A number or other social initiatives, such as voluntary organizations and businesses, are also relevant in this context, but they are not the principal focus of eParticipation. Technology-based interaction between the political sphere and the administration sphere, which does not involve citizens, is thus less in focus in eParticipation (Sæbø et al, 2008). As a research area, eParticipation is related to other research areas. eParticipation is a subarea of eDemocracy (Macintosh et al, 2003). If eDemocracy is concerned with the mechanisms that strengthen democratic decision-making through technology, then eVoting and eParticipation focus on the means to achieve this. The main differences between the three: eDemocracy concerns itself with the structural democratic relationships in a society. eParticipation better defines a set of technology-mediated participatory processes, while eVoting focuses on one particular participatory process common to all representative democracies, the way that technology helps to enact the process (Sæbø et al, 2008).

The disciplines that are most usually connected to eParticipation is political science, political and social theory, public administration and sociology. A smaller number of contributions comes from other disciplines such as information systems, computer science, communications and science and technology studies. Models of democracy are frequently used for characteristic forms of participation (DiMaggio et al, 2001; Lourenco \& Costa, 2006), while Habermas (1996) offers a more philosophical background for studying social participation (DiMaggio et al, 2001). A number of theories have been considered relevant, but only appeared inconsistently. DiMaggio et al. (2001) refer to innovation diffusion theories (Rogers, 1995), the network society (Dijk, 1999), and social capital (Putnam, 2000), among others. There is little common theoretical background on eParticipation, with an exception of theories from political science and political philosophy. Theories are used for a particular purpose by some researchers, linked to a particular theory or a particular research task (Sæbø et al, 2008). It is to be expected in a very young research area, there is little consistency or continuity in the choice of theories or research methods. There is no evidence of the emergence of a theory, or theories of eParticipation, whereas there is a considerable focus on the empirical examples.

eParticipation should be reviewed in the context of participatory culture. Contemporary eParticipation 'seeks to empower people with the help of Information and Communication Technologies, enable them to integrate in bottom-up decisionmaking processes, and to develop social and political responsibility' (Maier-Rabler \& Huber, 2010). ModernICTs offer more possibilities to citizens with regards to their political choices. The means to achieve participation in society and politics have been simplified. However, instead of making things easier for citizens with a variety of participatory means at their disposal, it poses greater challenges to them. If people want to move from occasional eParticipation to sustainable eParticipation, they need to learn how to make informed choices among the available ICTs and adequately use them. Acquiring capabilities for the informed usage of social media is therefore at the heart of modern participatory society (Maier-Rabler\& Huber, 2010). A participatory society is featured by its participatory culture. "A participatory culture is a culture with relatively low barriers to artistic expression and civic engagement, strong support for creating and sharing one's creations, and some type of informal mentorship whereby what is known by the most experienced is passed along to novices. A participatory culture is also one in which members believe their contributions matter, and feel some degree of social connection with one another" (Jenkins et al, 2006, p. 3). The classifications of participatory activities individuals are engaged in reflect different perspectives from the different bodies of literature, ranging from the institutional to the individual. These classifications can include different forms of public participation which connect the individuals and the State, as well as social participation or individual acts of engagement, and this has led to our three-fold classification of public, social and individual participation (Brodie et al, 2009).

More specifically, public participation is the engagement of individuals in the various structures and institutions of democracy. This form of participation is often referred to as political participation. A good example to understand political participation is the act of engaging people to make their voices heard and giving them the right to influence these decisions that affect them, as well as enhancing the delivery of services (Cornwall, 2008; Involve, 2005). These meanings of public participation often privilege an institutional perspective and focus on the engagement of individuals in decision-making processes within existing political structures. Social participation refers to collective activities that individuals may elaborate as part of their daily routines. It is associated with an individual's associational activities in both formal and informal contexts (Jochum et al, 2005), and include cultural or voluntary and community engagement (Jochum et a., 2005). People often 
choose to participate in associational life for a range of reasons that may have little to do with the State or the institutions of governance. People also engage on an individual basis. In this category, participation is based on an individual's personal values and worldviews as much as on personal experiences. Individual participation covers the choices that individuals make as part of their everyday lives, and reflects on the kind of society they wish to create and live in (Brodie et al, 2009). Within each of these three broad forms of participation there is a great number of individual participation activities, which can overlap between public, social and individual participation.

\section{The Potential of Social Media}

Participation is a key feature of a democratic nation, despite the varied forms of democracy existing. The liberal democratic approach considers elections as the central element of a democracy, while the deliberative theory of democracy includes public discussion and consultation of the citizens during the legislative process (Maier-Rabler \& Neumayer, 2008). Therefore, societal and civic dialogue is an important part of political participation. The vision that new Information and Communication Technologies (ICTs) would increase citizen participation and especially among youth, has always followed the introduction of new media. The internet due to its interactivity and its nature as the promoter of user-generated content was perceived as a technology that would encourage democracy and participation. Nowadays, the internet and internetbased technologies are in the centre of communication infrastructure for developed economies. The use of positive potential of ICTs is a new challenge for both politics and society. ICTs can help to actively engage more citizens and - especially youth into politics.

According to Fuchs (2008), communication and cooperation can be ameliorated by Web 2.0-technologies due to their new 'architecture of participation' (O'Reilly, 2005). The collaboration, decentralization and universality of the user-centered applications supports the transformation of the user into a producer and thus a more active aspect of the process (Birdsall, 2007).More importantly, for those who are skeptical about traditional forms of participation, the internet and Web 2.0 applications can serve as a channel for political engagement. Meaningful preconditions for eParticipation to ensure the democratic and political potential of ICTs are necessary, as well as the commitment of the existing political system for their protection (Maier-Rabler \& Neumayer, 2008). These assumptions are in line with a participatory perception of democracy that merges eParticipation into the process of civic engagement.

Social media represents today a too high share of internet traffic ${ }^{1}$, as people spend more and more time on social media sites, such as Facebook, YouTube and Twitter. The internet is a vital part of modern generations' lifestyle and especially appealing to the youth. With the turn of the millennium, the character of the internet changed rapidly by Web 2.0 applications such as MySpace, Facebook or Wikipedia (O'Reilly, 2005). These types of online activities are perceived by most people as trendy, easy and appealing, leading us to note that the strengths of social media are the alleged weaknesses of the pioneering eParticipation projects (Sæbø et al, 2008). Social media platforms are lowering obstacles to access and participation in conversation compared to governmental services. Participation is made easy in numerous ways, as for example, through national and local government adopting social media channels for citizen communication; or community groups using social media to engender community action. More importantly, this participatory culture creates the perception that developments can help modern democracies to include their citizens in the political process. Therefore, the use of social media can be considered as an effective way for filling in the gaps that prevent eParticipation from becoming part of people's lives.

The features of Web 2.0-based democracies extend the capabilities citizens have, in order to participate actively in democratic processes. Allegedly, the use of social media can: a) raise general awareness of important issues, b) make eParticipation platforms more accessible to audiences that are not involved in political discussions and c) utilise the newest trends in online communications to its advantage, making users' participation easier and more intuitive (Lacigova et al, 2012). Additionally, to address the political participation gap by the means of the internet and social web, closing the digital divide between the social media literate and illiterate must be set as an equally important goal. If eDemocracy policies aim to enhance and support civic participation, then the average individual citizen has to be empowered to the maximum in his

\footnotetext{
${ }^{1}$ More than half of the world internet user have a social media account on the most popular sites, i.e. Facebook, Twitter and Pinterest, according tolnternet Live Stats, http://www.internetlivestats.com/.
} 
ability to participate in the democratic procedures (Maier-Rabler \& Hubler, 2010). The social web is not simply a solution to the democratic question, rather than a challenge to its improvement.

Access to information is the main argument for complimenting new information and communication technologies as an enabler for citizen participation and thus more democracy in the society. Moreover, it is understandable that access alone is not enough and that people need to develop skills and literacy to acquire the desired information. Hardly ever this missing link between access and literacy, which is motivation and interest for political engagement receives enough attention (MaierRabler \& Hubler, 2010). In ICT-favoured circles, people learn to handle new technologies and social media at ease, but this is not the case for most average citizens. To actually encourage people to use the newly acquired skills for participatory purposes, further motivation and guidance is needed. The integration of the two separate spheres of formal education in school and informal ICT learning in computer-based spaced would be vital to the support of development of civic and political engagement.

In order to illustrate the importance of using social media as an enabler for eParticipation, the validity of the above claims has been proven by demonstrating the utilization of social media by currently running eParticipation projects. OurSpace ${ }^{1}$ sets the perfect example: an open-source social networking, designed to provide a forum for large groups of young people, regardless of nationality or language. The OurSpace project was an initiative of nine organisations from six European countries (Austria, Belgium, Greece, UK, France and Czech Republic) and was funded by the European Commission under the ICT Policy Support Programme in 2013. OurSpace included the commonly used features, such as user's profile, invitations, recommendations, rating and statistics, in a more appealing to young audiences way. Additionally, is had reached out to wide audiences by its own Android App, iGoogle gadget and a Facebook app, enabling mobile access to the platform and adjusting to the current trend that an increasing number of people use their mobile phones rather than their laptops to engage in online activities (Lacigova et al, 2012). The promotion of OurSpace on popular social networking sites, such as Facebook and Twitter, generates daily a wide user base from young audiences. In conclusion, the use of social media for increasing eParticipation can be a valid, cost-effective way to establish participation in policy projects, by promoting them as part of people's everyday lives.

\section{The value of eParticipation in modern democracies}

Participation has become a motto in modern societies. Not only frequently used by policy-makers, it is also seen as a synonym of engagement, involvement and empowerment, in a context that involves 'public' or 'community'. Generally, the advantages of participation relate to service effectiveness and efficiency, decision-making quality and legitimacy and active citizenship (Smith \& Dalakiouridou, 2009). In this chapter, we will examine the terms and social value of eParticipation, and summarise the current state of research in this field. Our analysis is focused on whether Information and Communications Technologies or electronic forms of participation enhance democratization and how.

The use of ICTs in the interim of democratic participation has made public participation more engaging to more target users, including citizens living abroad, younger generations, companies and organizations that had limited access to participation before. Medimorec, Parycek and Schossböck studied the influence of the ICT penetration on participatory democracy, in the Eastern Europe and Austria, and they observed a parallel shift of democratic mindset alongside internet penetration (2011). One of the many advantages of eParticipation was linked to the flexibility it offers in terms of time and location. Another one is the variety of choices offered to its participants. One sense of flexibility can be geographical, but flexibility can also define adjustable timing. Online services can be set up quickly and easily be adapted to different needs and are more up to date than offline tool (Medimorec et al., 2011). Additionally, eParticipation offers different forms of information, giving users the possibility to decide which services they need to use, how to access them and what kind of information they wish to have. It should, however, be noted that despite the length of opportunities provided are readily available, not all governmental sites take advantage of the possibilities on offer. A past review of state and federal government websites in the US revealed that key features that would facilitate connections or interactivity between government and citizens, such as email, comments or complaints, chat rooms, search features, broadcasting of government events, and website personalization were readily available for use. However, most governmental sites have not made enough progress at incorporating these democracy-enhancing features (West, 2004). 
Personalisation allows users to customise and personalise their profiles, therefore increasing the usability of online services and applications. Interactivity is another major advantage. Today there are a number of ways users can provide feedback using a range of aspects, such as maps, construction documents, Web 2.0 modules or other interactive means (Medimorec et al., 2011). Interactivity improves the services offered by public administration, especially because it allows prompt reactions and the ability to provide more information when needed, thus improving relationships with users. Most US governmental websites reviewed between 2000 and 2001 increased their potential of communication because they included features of two-way interaction (West, 2004). Modern and interactive ICTs offer numerous opportunities to the user, to communicate simultaneously and non-simultaneously at the individual or collective level. According to producers of civic websites for youth, many young people are frequently contributing to websites, creatively engaging in invitations to join, to have their say and to represent themselves. The research project UK Children Go Online (UKCGO) investigated 919 year old users of the internet in the United Kingdom to find an increasing virtual engagement on behalf of the youth (Livingstone, 2010). The role of the youth and essentially the hope that ICTs can lead to more participation of youth, to more political awareness and increased engagement is evident in the eParticipation efforts, regardless of the fact that many initiatives fail to achieve that through implementation. A number of youth-targeted surveys were conducted in Austria to record the preferences of youth in political participation, the internet and Web 2.0 technologies. The results highlighted a reverse ration of interest between traditional politics and Web technologies: the more increased interest for Web 2.0 technologies one had, the more decreased an interest in traditional politics was expressed. (Maier-Rabler \& Neumayer, 2008). It was, hence, assumed that Web 2.0 technologies can play an important role in the revitalization of political participation.

Other social utilities of eParticipation (and eGovernment, in general) include the ability to envisage policy, to offer to citizens the means to control the government and its policies, to balance the power of lobbies, to avoid corruption and to foster active citizenship, all with the long-term objective of strengthening representative democracy. Therefore, according to an OECD (Organisation for Economic Cooperation and Development) report, the objective of technology-enabled information dissemination, consultation and participation is to improve the policy-making process through a range of mechanisms designed for (2003):

- Engaging with a wider audience through counsel and participation technologies, which are adjusted to broader participation.

- Providing relevant information, in an accessible and comprehensive format, to the target audience in order to enable more informed participation.

- $\quad$ Enabling in-depth consultation and supporting online advisory debate.

- $\quad$ Encouraging the analysis of contributions to improve policy.

- $\quad$ Providing relevant feedback to citizens to ensure transparency in the policy-making process.

- $\quad$ Monitoring and evaluating the process to ensure continuous improvement.

- Therefore, it is important to distinguish the level of participation, the technology used, the level of the policymaking process and various other issues, which include the benefits that online participation potentially offers (Macintosh, 2004).

Based on data provided by the European Commission, many people today are losing interest and trust in the way their governments proceed with policy-making (Gatautis, 2010). There are issues of trust, openness and transparency, which remain the main concern, as the public lacks of confidence in governmental institutions (Panopoulou et al, 2009). In the meanwhile, public indifference and dissatisfaction is massively expressed through low turnout rates at elections, which further lead to representatives elected by a minority of the electorate. In this context, citizens increasingly demand greater transparency and accountability from the government, and favour public participation in the shaping of policies that they become the subject of (Gatautis, 2010). For these reasons, participation is gradually gaining vital importance in modern societies. The pursuit of governmental goals involves an effort to mobilise individuals, groups and communities, through perceiving active citizenship both as a responsibility as well as a right. Thus, participation starts develop in a moralising rhetoric, a functional condition of the state and a regulating discourse (Smith \& Dalakiouridou, 2009). Empowering people and inviting them to 'cooperate' and get involved with the government is a key strategy to achieve the welfare state they demand.

eParticipation has become a key strategy with regards to the democratic deficit that Europe is facing. The term democratic deficit has appeared in connection with the EU, above all to indicate the opaqueness of decision-making (Smith \& 
Dalakiouridou, 2009). Great effort has been put into the upgrade of transparency and accountability in public power in the $\mathrm{EU}$ and the enhancement of its legitimacy. "Transparency is perceived as a necessary condition for democracy, as it ensures that citizens obtain all the information they need to call public authorities to account. Legitimacy demonstrates the capacity of European institutions to provide a system of good governance and fulfil their functions in an impartial manner. Citizens and other actors reflexively assess both the processes and the outputs of governance in terms of their legitimacy" (Smith \& Dalakiouridou, 2009, p. 4). A number of initiatives promoting transparency and accountability have already been initiated by EU institutions, to evidently provide citizens with more opportunities for information, but in reality citizens feel insecure in front of increasing amount of information and remain reluctant to form their future as Europeans, an insecurity which results in a passive expression of citizenship (EACEA, 2013). The following good governance principles were formulated as an answer to the perceived mistrust of European citizens in the European structure. From 2000 onwards, the policy documents adopted by the European Commission make a clear reference to the transparency and accountability needed, while from 2002, consultations are given more importance as a citizen contribution to the policy-making.

The EU Research Framework Programmes 5, 6 and 7, following the logic of the first four framework programmes (19841998) for the support of the community research and technological development,have addressed various technological issues and tested a range of eParticipation services. More specifically, Framework Programme 5 launched an important number of projects to enable the online participation of all stakeholders in decision-making, in topics such as the improvement of interaction between citizens and public administrations, on-line mediation systems for citizens and their representatives, the enhancement of the former's participation etc (Chrisaffis \& Rohen, 2010). The current framework programme (2014-2020), ambitious Horizon2020, continues to direct policy-making in Research and Technological Development, under the auspices of the European Commission.

\section{Design of digital participatory public services}

eGovernment development is based on strategic planning, usually under the responsibility of national governments, which defines the common targets set for public administration: modernised services, with low cost and time minimization for public service execution and the development of improved, citizen-centered practice. A number of tools, which are used to increase eParticipation, have been identified, also referred to as eMethods and includes many of the functionalities that we are already aware of, such webcasts, FAQs, blogs, chat rooms or discussion forums. These web-based tools cover many areas of participation, such as legislation, policy-making or social action.

Generally, the development of eGovernment strategic plans is a top-down procedure, which means that central governments supervise the design and execution of national eGovernment initiatives. The top-down procedure is defined with means of educational methods, as a scheme where the instructor presents the general conception of a system and then proceeds to its subsystems (Jorgensen, 2005). In eGovernment initiatives, the instructor is the central government, who plans and monitors multiple projects. Top-down eGovernment plans contain policies and project goals, but not methods and principles. Information and Telecommunication Technology vendors provide mainly eCommerce-based applications as solutions for eGovernment and for digital service execution, after being transformed and adapted to public administration methodologies (Lowry et al, 2002). Another approach to eGovernment design is the bottom-up procedure. A bottom-up approach, in contrast to top-down, refers to a decentralised procedure of eParticipation, which allows for individual research to design and drive their own projects in a controlled environment, while targeting and prioritizing specific problems and then expanding to a wider system architecture (Zissis et al, 2009). Interestingly enough, surveys on eGovernment show that although a number of eGovernment initiatives achieved their goals in time and cost savings for both citizens and public administration, the design procedure of national governmental planning creates problems to eGovernment reception by both citizens and public administration (Anthopoulos et al, 2007). Skepticism incommodes governmental planning, with regards to the success and development of eGovernment.

Each one of the eMethods used to support eGovernment projects are accompanied by a SWOT analysis. SWOT, which stands for 'Strengths, Weaknesses, Opportunities and Threats' analysis is a descriptive method used to identify and list positive or negative factors about an issue, in a more consolidated way. In the final stage, all the data from the SWOT models are combined in one form, in order to make a comparison between eParticipation tools. The first step for the SWOT analysis is to establish a series of criteria. These criteria are thoughtfully selected in order for the balance to be maintained after technical and social requirements (Anthopoulos et al, 2007). There is a number of technical requirements to enable the effective implementation of eParticipation tools. The first and foremost prerequisite is related to security and privacy in 
the eParticipation context. eParticipation services need to be user-friendly, as simple as possible and time-effective, in order to ensure the participation of users. The value of security and privacy measures is high, not only to ensure that users will use but to trust the system, as well. A lack of trust on the security variables of the system will result in low participation rates and thus an ineffective system. Thus, the proper balance of between security, usability and openness is highlighted as vital in the effort to implement effective eParticipation services (Fraser et al., 2006). Anthopoulos et al. identify a number of technical requirements to facilitate this implementation (2007), such as: a) deployment complexity (i.e. how difficult the deployment of an eParticipation tool is), b) Information richness (i.e. the amount of information the specific eMethod is able to contain) c) Security (e.g. in the case of a user's navigation), d) Interactivity (i.e.g. to what degree are the communication channels interactive), e) Scalability (i.e. how effectively can the application scale up to a broader public).

The variation of necessary parameters to be taken into account show that, thanks to design choices and software features that promote participatory behavior and trusted consultation, citizen-oriented services are more than an online area where citizens can only report problems for their local government. Much more importantly, they create an environment where, due to changing political circumstances, the social actors can undertake a variety of actions to cope with actual problems (De Cindio, 2012). Research suggests that this variety of design choices and software features enhance engagement around open data, as they enable conversations around them and promote people's collaboration on issues that involve data. From a technical point of view, the tools that support data analysis are absolutely necessary, but there is also an increasing demand to explore tools that support social communication and interaction, as well (Davies, 2012). Undoubtedly, more research interventions will add value and increase the understanding of data use and support the development of improved strategies for data engagement. However, when studying a policy initiative depending of technology, one should always anticipate that emerging technologies will eventually challenge the framework and its ability to deal with new concepts, tools or applications. At the same time, it will be tested by the success, failure, results and difficulties of each specific case based on the rule that all successful models evolve through exploration (De Cindio, 2012).

\section{Developments in eParticipation}

Recent initiatives based on the analysis and assessment of democratic systems offer theoretical and empirical insights towards the development of eDemocracy frameworks. From a theoretical point of view, those initiatives support developments in the democratic process; while from an empirical point of view, they contribute in identifying formulas and criteria for the evaluation of practices, which can be relevant for offline and online modes. Here, we consider tools and methods that directly promote citizen participation in policy-making rather than the ones that support group discussions only.

\section{eVoting}

Electronic voting (eVoting) refers to the ability to vote via the internet. eVoting refers to both the electronic means of casting a vote and the electronic means of arranging votes. In some countries, punch cards (e.g. USA) and optical scan cards (e.g. Germany and Scotland) are tabulated using electronic means, and they have been in use for decades. Electronic voting in polling stations is being used in some of the world's largest democracies, such as France, Italy, Netherlands, and Norway etc. A number of EU member-states, including Czech Republic, Finland, Greece, Latvia, Lithuania, Romania and other, are currently developing pilot programmes of eVoting systems to improve various aspects of the electoral process (Ace, 2010). eVoting is often seen as a tool that helps to advance democracy, to build trust in electoral management and add credibility to the electoral process. The technology is rapidly evolving to invite election managers, international organizations, vendors and authorities to continuously update their methodologies and approaches(IDEA, 2011). In recent elections, internet voting has attracted wide interest, creating hopes that communications technologies may lead to increased voter turnout, and the inclusion of voting groups that had abstained from elections. Estonia was the first country in the world that allowed internet voting in the 2007 national parliamentary elections, and has thereafter served as an important case for studying the state of eDemocracy (Bochsler, 2010).

Specialized techniques used in other domains have been proposed to contribute to the development of eVoting systems. These techniques aim to bring a higher level of competitiveness in the design and implementation of voting systems. Helios is the first web-based cryptographic eVoting system.It has a single component and uses a public bulletin board (Adida, 2008).A. F. N. Al-Shammani, A. Villafioritat and K. Weldemariam describe the consecutive phases of voting (2012). In 
registration phase, voters first obtain their password via email. Helios separates the process of voting in preparation from casting. Anyone using the system can check the authentication of the ballot, since every user is given only at ballot casting time. After the ballot has been completed from the user side, the voting system proceeds with the encrypted vote by displaying a sign of the ciphertext. The preparation of the ballot can either be audited, or the ballot can be cast after the voter has been authenticated. In the case the vote decides to audit the ballot, the ciphertext and the randomness used for encryption is displayed, which allows the user to check that the vote was properly transformed into the ballot. As soon as the ballot is cast, the voter receives a hash for the encrypted vote, which is also posted on the BB next to his name. In tallying phase, the ballots are mixed and decrypted, providing proofs of correctness for both steps.

During the past two decades, researchers have been developing verifiable eVoting systems, however only few of the developed systems have been used in real-world elections. The eVoting systems that have been used in large countries, such as India, Brazil and the US are unverifiable and there have been concerns about security implications. The biggest problem with developing verifiable eVoting technologies seems to be the public distrust on responsible authorities. Since 2013, Dr. Feng Hao's has been developing a project that aims to devise a secure eVoting system: "We aim to provide a means whereby voters can independently verify that their votes are accurately captured and tallied by the system; ensuring that the integrity of their vote is maintained. In the process, we eliminate reliance on authorities who tally the cast votes, so the election is self-tallying" (Hao, 2014). In the EU the eVoting initiative is still in the beginning. Estonia was the first country to start an actual eVoting project in 2003, which has been used in the 2005 local government council elections for the first time, to continue its success with the national elections in 2007 and every 4 years ever since. Germany and Netherlands that were using electronic voting machines since 1998, stopped their eVoting projects in 2009 and 2008 respectively, until further testing is completed (Ace, 2010). In the case of Germany, it was suggested that the use of voting machines was "unconstitutional", while the Dutch government decided to address security concerns and other issues emerged by returning to paper voting (NDI, 2014; NDI, 2014a).

\section{eConsultation}

eConsultation designates interactive online platforms where citizens, civic actors, experts, and politicians gather to provide input, consider, inform and influence policy and decision-making. Introduced by political institutions or non-state actors, eConsultation can take different forms, target on different groups or issue areas, in the use of technical tools at which they are launched (Coleman \& Gøtze, 2004). Sometimes, they incorporate spaces for citizen-to-government as well as citizento-citizen interactions. What makes eConsultation unique in comparison to other spaces of the virtual public sphere, is the ability to cause influence on the policy-making process. Informal electronic spaces such as virtual communities, local forums, chat rooms and participants interact in a way that allows them to exercise political influence (Tomkova, 2009). The goal of eConsultations is to affect formal political and decision-making processes. Additionally, the purpose of eConsultation has been to enable citizens with relevant experience and expertise to inform and advise legislators on specific areas of policy (Coleman \& Gøtze, 2004). eConsultations is a more formal and organised form of eSpace compared to other forums or digital attempts in the virtual public sphere. They tend to have a set duration, agenda and pre-defined topics for discussion by the host. Given that it is government agencies that usually start eConsultations and not individuals, the difference in level between the actors involves variation in levels of authority, expertise and access to decision-making processes (Tomkova, 2009). Your Voice in Europe ${ }^{1}$ is the European Commission's 'access point' to a number of consultations, discussions and other tools allowing citizens to play an active role in the European policy-making process. It is argued that eConsultations provide functional and deliberative communication benefits, enhance social inclusion and citizengovernment interactivity and make public policy making processes more transparent and legitimate.

\section{ePolling}

Online polls are another type of eConsultations offering snapshots of civic temperature on a specific public issue. As a quick web-based survey, ePolling allows participants to select one answer from a list of alternatives in response to a simple statement or question. Once an answer has been submitted, current poll results are usually displayed along with relevant numbers or percentages. Typically there is no collection of personal or demographic information. Therefore, unless users'

\footnotetext{
${ }^{1}$ Your Voice in Europe, http://ec.europa.eu/yourvoicel.
} 
Internet Protocol (IP) addresses are logged in, it can be difficult to stop participants responding more than once. Quick polls are generally employed as light-weight, fun e-tools, rather than contributing to any weighty policy debate (Macintosh et al, 2005). Examples of more elaborate ePolls or eSurveys include the ones utilised by the EU Commission, as part of the Your Voice elnitiative, while the simpler one-shot polls appear as a sub-feature on government websites.

eDeliberative polling combines online deliberation in small group discussions with random sampling to facilitate public engagement on specific issues. A variety of these surveys and discussion forums support such this eDeliberative polling. Directly addressing the issues raised by traditional offline engagement techniques for policy development, ePolling has a major advantage: it involves the public in all key issues. The concept of deliberative engagement address the problem by prompting the gathering of public views by a process of deliberation. Although the potential for eDeliberative polling has been recognised by a number of well-respected organisations, such as the Internet Corporation for Assigned Names and Numbers (ICANN), it yet lacks to be its wide application in the local government context (Macintosh et al, 2005).

\section{ePetitioning}

The so-called web-based system hosts online petitions and allows third parties to be signed up to by addition of their name and address online. ePetitions are another form of eConsultation which enable citizens to enlist issues, complaints or requests directly to the government. Usually, the names and addresses need previous verification, but as ePetitions are only informing the local councils about an issue, and not presenting it (which will lead to legal enforcement), the level of control does not need to be the same as for eVoting. Additional features can enhance the quality of ePetitions and the transparency of the process (Macintosh et al, 2005). In some cases, an integrated discussion forum can be incorporated in order to offer the users the possibility to argue about their support on certain petitions. The format and procedure followed in ePetitions varies from local government to local government. In modern democracies, this form of participation is legally integrated. In the EU member-states, for example, the right to petition is protected by national constitutions and in some cases European regulations (Riehm et al, 2011). They are mainly intended to serve as a bottom-up participatory tool, but they have also been hosted by governments (Tomkova, 2009). UK government's popular 10 Downing Street and the European Parliament's petitions initiative set a good example of such online spaces (Tomkova, 2009).

Generally, the right to petition ensures access to all institutions of the political-administrative system at all levels (state, regional, local). However, in some cases specific institutions are established to act as responsible for the processing of petitions. These institutions play the role of mediator between citizen and executive power and maybe even an advocate of the petitioner (Böhle \& Riehm, 2013). From a study conducted in 29 countries (EU member-states and Switzerland), a total of 59 national state-level parliamentary petition bodies and ombudsman institutions were identified (see table below). In the majority of these countries, there is a pattern where both a parliamentary petition body and an ombudsman institution processes petitions to the parliament (Böhle \& Riehm, 2013). Seven countries do not support the possibility of petitions to parliament (Cyprus, Denmark, Estonia, Finland, Ireland, Latvia, and Sweden), while only three of the 29 countries (Germany, Italy and Switzerland) have no parliamentary ombudsman institution at all. 
Table 2: Possibilities for petitioning national parliaments.

Note: • Petition system provided; - No petition system; - No upper house.

\begin{tabular}{|c|c|c|c|}
\hline \multirow{2}{*}{ Country } & \multicolumn{2}{|c|}{ Petition body/institution } & \multirow{2}{*}{ Ombudsman-Institution } \\
\hline & Lower house & Upper house & \\
\hline Austria & $\bullet$ & $\bullet$ & $\bullet$ \\
\hline Belgium & $\bullet$ & $\bullet$ & $\bullet$ \\
\hline Bulgaria & $\cdot$ & - & $\bullet$ \\
\hline Cyprus & $\circ$ & - & $\bullet$ \\
\hline Czech Republic & $\bullet$ & $\bullet$ & $\bullet$ \\
\hline Denmark & $\circ$ & - & $\bullet$ \\
\hline Germany & $\bullet$ & $\bullet$ & $\circ$ \\
\hline Estonia & $\circ$ & - & $\bullet$ \\
\hline Finland & $\circ$ & - & $\bullet$ \\
\hline France & $\bullet$ & $\bullet$ & $\bullet$ \\
\hline Greece & $\cdot$ & - & $\bullet$ \\
\hline Hungary & $\bullet$ & - & $\bullet$ \\
\hline Ireland & $\circ$ & $\circ$ & $\bullet$ \\
\hline Italy & $\bullet$ & $\bullet$ & $\circ$ \\
\hline Latvia & $\circ$ & - & $\bullet$ \\
\hline Lithuania & $\bullet$ & - & $\bullet$ \\
\hline Luxembourg & $\bullet$ & - & $\bullet$ \\
\hline Malta & $\cdot$ & - & $\bullet$ \\
\hline Netherlands & $\cdot$ & $\bullet$ & $\bullet$ \\
\hline Norway & $\cdot$ & - & $\bullet$ \\
\hline Poland & $\circ$ & $\bullet$ & $\bullet$ \\
\hline Portugal & $\cdot$ & - & $\bullet$ \\
\hline Romania & $\cdot$ & $\bullet$ & $\bullet$ \\
\hline Slovakia & $\cdot$ & - & $\bullet$ \\
\hline Slovenia & $\cdot$ & $\circ$ & $\bullet$ \\
\hline Spain & $\cdot$ & $\bullet$ & $\bullet$ \\
\hline Sweden & $\circ$ & - & $\bullet$ \\
\hline Switzerland & $\cdot$ & $\bullet$ & $\circ$ \\
\hline United Kingdom & $\bullet$ & $\bullet$ & $\bullet$ \\
\hline Total & 21 & 12 & 26 \\
\hline
\end{tabular}

Source: Böhle \& Riehm, 2013

The most important contribution of the petition systems, which is greatly enhanced by the help of the Internet, is the strengthening of the public participation. This is gradually coming into realisation, firstly, by designing ePetitioning systems in a direction that enhance democracy and secondly by ameliorating the democratic system itself as to be more open to dialogue and citizen participation. 


\section{eLegislating}

When it comes to legislation, the question that arises as a result of the synchronisation of the field by computing trends, is not only how it is possible to make digital laws, but also whether digital media will change the forms of law-making. The success of user-friendly software and websites has developed a great sense of convenience, which has become one of the major features and thus norms of online communication. The interactive, informative and engaging nature of the internet is what makes it popular to users, alongside with the simplicity of using its online libraries. Users that become familiar with informal, user-friendly cyber-formats may even come to reject the stiffness of conventional legal texts compared to the ones they access online (Howes, 2001). eLaw is a new concept, which is used in Europe since 2004. It refers to electronic legislation and to the different aspects of electronic publishing of legislation. eJustice is a similar concept, including the use of electronic technologies in the field of justice (European eJustice portals etc.). The EU Council has an eLaw and eJustice working group, exchanging information on the practices of EU Member-States and developing policies at the EU level. The European Commission has created EUR-Lex as a one-stop shop to European legislation (EUR-Lex which includes N-Lex, a portal of national legislation in EU Member-States) (Hietanen, 2012). EUR-Lex is estimated number of 13 million visits per month (Trafficestimate, 2015). European legislation today is made available in most of the European member-states free of charge. However, there are differences in the way legislation is made available. There are types of legislation varying from limited period legislation to legislation of the last century, consolidated or unconsolidated form with amendments etc. In some countries, the original versions of legal acts are available, while in others the consolidated versions of legal acts are also available. An eLegislation portal has a number of features that can either support the top-down flow of knowledge from the government to citizens. Based on a DMS (Document Management System) that is used to track and store electronic documents, eLegislation is capable of storing any type of legal document (Ona, 2013). It appears, thus, that eLegislation portals increase the volume of information that becomes available to the larger audience, making citizen participation more expansive. The main challenge, however, is the need to ensure that this increase in volume of information does not affect the role of such portals being meaningful and actionable.

\section{eCampaigning}

eCampaigning defines the use of 'new' communication technology, such as the internet and mobile telephones, in campaigning. eCampaigning can be a quick, cost-effective and efficient way of contacting, informing and mobilizing large numbers of people in contexts where electronic tools are easily accessible and widely used. World-wide data show that average internet use tends to increase more rapidly than gross national product (Rosling, 2006). eCampaigning involves both passive and active tools, often combined. Passive tools use a one-way communication: users receive information via email or by reading a website. During the last years, emailing, comment and posting functions on websites and blogs, social networks and other new technologies enabled two-way conversation, sometimes in real time, elevating the internet into an active tool (UN Women, 2012). Campaign messages can spread through social networks only with a mouse click, on a spontaneous, unregulated way that never could before.

Studies on the implementation of eCampaigns and eVoting in different European countries, show that the Internet is often associated with the professionalization of the voting process as well as the electoral campaigns (Norris, 2004; Norris, 2002). However, new concerns have arisen that relate to trustworthiness and identity in campaign management, and involve issues of targeting, personalization, complexity and negative campaigning. While, though, networked technologies promote public participation and engagement on a way not possible in the pre-digital era, they are as well source of tensions and conflicts which are posing new questions to traditional models of power and control, creating new balances (Marcheva, 2010). Therefore, the same technologies that could create spaces for public and networked engagement, may as well allow citizens to organize other than social gatherings or political protests, such as terrorist attacks.

The first tangible example of the use of ICT technologies in electoral campaigning comes from Spain, which went through a so-called "Americanization" of politics, following the successful pattern of the Obama social media campaign, in 2008. In the aftermath of 2008, Spain and Catalonia have embraced new technologies by opening up online channels for disseminating electoral content (Xifra, 2011). Three years later, the Finnish national elections showcased an extensive use of social media in the electoral campaign. Despite the fact that citizens' participation in eCampaigns was limited, there were indications of mobilization and 'potential of change' regarding the citizen activity (Strandberg, 2013). The 2009 European Parliament elections represent the first eCampaigning effort on a pan-European level, where many different online applications (Facebook, YouTube, Twitter, MySpace and Flickr) were used systematically (Vesnic-Alujevic, 2011). 


\section{Participatory Budgeting}

Participatory budgeting (PB) is the online process that allows citizens to participate in the decision-making process of budget allocation and it has been considered as one of the main innovations that aim to reinforce accountability on a governmental level. Thus, it belongs to the online public practices that reinforce democracy at both local and regional levels. It provides citizens with the opportunity to approach governmental operations and to participate, discuss and control the allocation of resources. "The enhanced transparency and accountability that participatory budgeting creates can help reduce government inefficiency and curb clientelism, patronage, and corruption. Participatory budgeting also strengthens inclusive governance by giving marginalized and excluded groups the opportunity to have their voices heard and to influence public decision-making vital to their interests" (Shah, 2007). Provided that it is administered properly, participatory budgeting can elevate governmental services and strengthen the quality of democratic participation.

Thus, it is not a coincidence that the inclusion of participatory budget practices in European states has increased. In the UK, the government expected to have PBs implemented at all administrations supporting local governments by 2012. Local authorities from Barnet, Northamptonshire and Maidstone used an online budget simulator to consult citizens on their preferences, regarding to the allocation of the budget (Daventry District Council, 2009). In Germany, after a pilot project in 2005 in Berlin, where the local council received budget proposals from citizens online, the city has repeated the operation. Since then innovative initiatives have been conducted in the cities of Cologne, Hamburg, Freiburg and Leipzig (Luehrs, 2009). Combining online and offline methods, in 2006 the city of Modena in Italy set an experiment in which citizens could send email suggestions while they were watching live video streaming of the meeting. The use of SMS in order to reach a broader and younger audience has been used in more Italian public budgeting processes, such as those of Rome, Bergamo and Reggio Emilia (Peixoto, 2009). According to Peixoto, the budgetary allocations were increased based on large citizen demand, and the amount of proposed workings was larger than the original planning provided (2009). Therefore, the participation altered the original budgetary planning both quantitatively and qualitatively.

\section{VII. eParticipation and European Good Practice}

The potential for ICT to alter the negative democratic balances across Europe and increase the level of political participation has been the subject of academic discourse. However, only relatively recently there has been adequate practical design and application of eParticipation to consider this potential in a real-world context. The development of such advanced information systems has enforced a growing community of research and practice which analyzes eParticipation. Current analysis includes understanding the role of technology in public participation and learning from the experience of European countries. The achievement of eParticipation initiatives is the relationship created between citizens and government assumed as one of a partnership. Since the promise of eParticipation is the ability to deploy ICTs to establish a partnership between governed and governing, as to neutralise the declining public confidence in democratic institutions and meet new expectations of increased popular participation in governance (Schmitter and Trechsel, 2004). eParticipation is, therefore, one of the reforms that representative democracies are currently experimenting with in the hope that participation counteracts public discontent. Estonia and Sweden have provided us with invaluable case studies from the study and practical application of eParticipation projects, in their democratic efforts to increase citizen participation.

Estonia, an EU member-state of 1.3 million inhabitants, has established a successful record of pioneering eParticipation projects, also known as the first country to introduce eVoting for the national elections of 2007 (Charles, 2009). One of the projects worth examining, both in terms of citizen mobilization and government response, was the eParticipation application known as TOM, which stands for "Today I decide" in Estonian (Glencross, 2009) kicking off in 2001. This was a pioneering move since it enabled Estonian citizens to participate in the national legislative process; other eParticipation initiatives around the world have been restricted to the local or regional level (Carman, 2007). Starting in 2001, the Estonian TOM platform provides until today a valuable model for understanding the dynamics of eParticipation. This Estonian case provides lessons for eParticipation in practice so that the expectations of users and government officials both benefit from such initiatives.

According to the OECD theoretical framework for categories of citizen engagement, the TOM platform fits the model for using Information and Communication Technologies to promote active citizen participation rather than providing information or as a consultation mechanism (OECD, 2001). At first, the TOM project was more ambitious than similar projects. Rather 
than being a simple medium for collecting signatures, the TOM tool became a forum for citizens to discuss legislative proposals, within a ten-day period following submission, and to vote upon them. After an idea been proposed by a user the system functions first allow for discussion between TOM users (participating citizens), then authors of legislative proposals have three days to amend them before they are voted by users. Once a proposal is voted by a majority, it is forwarded to the relevant government department, which then has a month to respond to the proposal explaining the argumentation behind an action. This formal government response is then posted on TOM (Glencross, 2009). The experience gained from launching and developing TOM and the central participation tool was further used as a model for international product such as TID+ ('Today I Decide' International'1), an open-source software that can be used for the collection of public proposals (Åström et al, 2013). A number of legislative ideas were discussed and gained momentum on TOM, such as traffic policy, taxes, constitutional affairs, crime and alcohol policies (Glencross, 2009).

The Interregional Cooperation Programme INTERREG IVC, which is financed by the European Union's Regional Development Fund since 2010, records successful eGovernment programmes throughout the European Union (Lukka, 2010). The city of Tartu in Estonia has followed a successful pattern to update the electronic profile of the city. The local authorities decided to involve the Tartu residents in this process from the beginning. At first, the city residents contributed with their opinion on the new website's schemes, and in the second phase, the website architecture was built. A number of methods were used to engage citizens; from public polling to testing of navigation, the needs and wishes of the ordinary people were taken into consideration about the new website. The goal of the project, which was to create a standard methodology and a working prototype with maximum involvement of the city residents, was achieved. The project, also, has been a huge success because the city residents participated actively and expressed interest, the methods produced results and the project was completed in a timely manner. The most important thing was the chance that the city residents were given to express their opinions and the subsequent efforts have relied on those opinions. Social media proved extremely helpful as well; Facebook was used to achieve communication with the city residents, including posts inviting all to take part in the public poll and share their ideas about the website. During the second phase, at the creation of the website prototype, fewer participants were considered which, however, secured a high quality of results, because the ones involved were motivated and competitive enough to ensure effectiveness.

In Sweden, at the local level, eParticipation initiatives are only a few. However, they offer important examples of eParticipation practices run by Swedish local authorities. A number of online 'deliberative referendums' were undertaken in small cities such as Malmö, Vara and Sigtuna. In the city of Sigtuna, ten online referendums were conducted in one year and the results were promising: a relatively high percentage of citizens took part in these online referendums (30-60\%) and the contributions made by participants did have an impact on final policy decisions (Åström et al, 2011). Other initiatives include the Gothenburg Online Forum and the Malmö Initiative. In 2004, the city of Gothenburg launched an online forum with regards to a redevelopment project, in their effort to create new structures for policy-making and planning (Benesch and Ullmark, 2008). The redevelopment of the city Södra Älvstranden included two challenging tasks: a) the planning and development of the municipal area with the minimum financial impact on the taxpayers and b) and the broadening of citizens' participation.

To achieve the attraction of investors in the area and enhance citizen participation, the municipality contracted a company named Ävstranden Utvecklings $A B(A ̈ \cup A B)$, which was responsible for both urban planning for the indirect dialogue with citizen (Åström et al, 2013). The following dialogue with citizens was conducted in two ways: an online forum and an exhibition at the City museum. By November 2006, 980 posts had been registered on the forum. Many contributions were direct proposals and opinions focusing on the city life, housing, transport, environment and the new city look. In the end, the impact of citizen participation was valued as limited and it was noted that citizens and decision-makers had different perceptions about the development of the process. Citizens taking part in the online debate expressed expectations about an open process where participation would directly influence the process, while representatives of ÄUAB and the planning department supported the view that 'online deliberations' preceded formal planning, in any case (Åström et al, 2013). Despite the subsequent dissent, the Gothenburg Online Forum serves as model of citizen participation in terms of sharing problems rather that sharing power.

The first ePetitioning system was launched in 2008 in the city of Malmö. The most defining aspect of ePetitioning systems is the willingness of public authorities to take petitions seriously when preparing an institutional plan. In a similar to the Gothenburg case, broadened participation was achieved in quantitative terms with nearly 200 ePetitions in the first year.

\footnotetext{
${ }_{1}^{\prime}$ Today I Decide' International,http://tidplus.net/.
} 
But the political and administrative decision-makers refused to give a formal response to petitioners, which the petitioners themselves had taken for granted. One year and a half afterwards, the actual participation in the Malmö petition system added up to 210 initiatives and 5,500 signatures (SALAR, 2010). On a survey that asked the petitioners what motivated them to participate in the Malmö Initiative, they replied that simplicity was crucial. Additionally, the collection of online signatures is important, as well as petitions' ability to generate awareness and publicity in local media (Åström et al, 2013). What is even more crucial, though, is the potential to address democratic concerns in real political issues, the time they arise.

\section{Conclusions}

Lately electronic participation has evolved enough to start re-engaging citizens with the democratic processes by exploring the potential of ICT in the public sector. At the academic level, a number of frameworks have helped us to understand eParticipation, through the most familiar disciplines and social initiatives that approached contemporary models. At the practical level, a large number of eParticipation initiatives have been launched at all levels, some with larger success than others. In this article, we examined the use of ICTs and the main aspects of eParticipation initiatives from a social and political perspective. Additionally, we provided an understanding of the progress and current trends of eParticipation. For that purpose, we summarised the European experience with eParticipation and analysed information gathered from the relevant literature and the implementation of political initiatives.

In general, it can be concluded from the research that there is increasing activity in the field of eParticipation in Europe, as well as there is a number of exceptional initiatives already implemented and fully operational. However, there are still many opportunities to be explored and a lot to be achieved with the cooperation and sharing of good practice between countries and regions, but also across the different levels of participation (Panopoulou et al, 2009). Furthermore, practical implementation of eParticipation initiatives suggests that the scope of eParticipation initiatives narrows the potential outcome, allowing more active participation and more specific outcomes. This empirical conclusion could be the basis for further consideration of the prospects and restrains of eParticipation. It should be further examined whether eParticipation can indeed essentially involve the public and in what ways this could be achieved. Hopefully, the research presented in this article will contribute to the future work and research of eParticipation developments and will facilitate the transfer of eParticipation good practice.

Yet, one of the greatest challenges to eParticipation is the fear of unfulfilled expectations. Based on Hirschman's model it appears that eParticipation models alone are no solution for the problem of public distrust of political institutions. Citizen participation may be successful in the promotion of loyalty only if the use of the participation leads to reform; when participation seems pointless, the result is simply disengagement (Hirschman, 1994). From this perspective, governments seeking to implement eParticipation will be successful only if citizens' willingness to trust the eParticipation process can be sustained, and if the system has notable effects on the legislative decision-making process. Thus, the government's willingness to take eParticipation initiatives to the next level should be evaluated not only on the basis of planning and implementing such opportunities, but indeed taking into consideration the outcome of citizen participation. In that matter, citizens are concerned by the extent to which their participation counts as important.

\section{BIBLIOGRAPHY}

[1] Ace (2010) The Electoral Knowledge Network, Aceproject.org. Available from: http://aceproject.org/aceen/focus/e-voting/countries

[2] Adida, B. (2008) "Helios: web-based open-audit voting", Proceeding of the 17th Conference on Security Symposium, USENIX Association: Berkeley, CA, p. 335-348.

[3] Al-Shammani, A. F. N., Villafioritat, A. and Weldemariam, K. (2012) "Understanding the Development Trends of Electronic Voting Systems", Paper of the Seventh International Conference on Availability, Reliability and Security (ARES), August 20-24th, Prague.

[4] Anthopoulos, L.G., Siozos, P. \& Tsoukalas, I. A. (2007) "Applying participatory design and collaboration in digital public services for discovering and re-designing eGovernment services", Government Information Quarterly, Vol. 24, Issue 2, pp. 353-376. 
[5] Åström, J., Granberg, M., Khakee, A. (2011) "Apple Pie-Spinach Metaphor: Shall eDemocracy make Participatory Planning More Wholesome?", Planning Practice \& Research, Vol. 26, No. 5, pp. 571-586.

[6] Åström, J., Jonsson, M., Hinsberg, H. \& Karlsson, M. (2013) "Case studies on eParticipation policy: Sweden, Estonia and Iceland", Tallinn: Praxis Policy Center.

[7] Benesch, H. \& Ullmark, P. (2008) "The Experimental Start of the Planning of Södra Älvstranden in Gothenburg", ArtMonitor, Vol. 5, pp. 28-33.

[8] Birdsall, W. F. (2007) "Web 2.0 as a Social Movement", Webology, Vol. 4, No. 2. Available from: http://www.webology.org/2007/v4n2/a40.html

[9] Böhle, K. \& Riehm, U. (2013) "ePetition systems and political participation: About institutional challenges and democratic opportunities", First Monday, Vol. 18, No. 7. Available from: http://firstmonday.org/ojs/index.php/fm/article/view/4220

[10] Bochsler, D. (2010) "Can Internet Voting Increase Political Participation? Remote Electronic Voting and Turnout in the 2007 Parliamentary Elections", Paper presented at the 'Internet and Voting' Conference, June 3-4, Fiesole, Italy.

[11] Brodie, E., Cowling, E., Nissen, N., Paine, A. E., Jochum, V., Warburton, D. (2009) "Understanding participation: A Literature Review", Involve. Available from: http://www.involve.org.uk/assets/Üploads/Pathways-literature-review-final-version.pdf

[12] Carman, C. (2007) "The Process is the Reality: Perceptions of Procedural Fairness and Participatory Democracypost", Political Studies, Vol. 58, pp. 731-751.

[13] Charles, A. (2009) "The Electronic State: Estonia's New Media Revolution”, Journal of Contemporary European Research, Vol. 5, No. 1, pp. 97-113.

[14] Coleman, S. \& Gøtze, J. (2004) Bowling Together: Online Public Engagement in Policy Deliberation, Hansard Society: London.

[15] Cornwall, A. (2008) "Unpacking 'Participation': models, meanings and practices", Oxford University Press and Community Development Journal, Vol. 43, No. 3, pp. 269-283.

[16] Chrisaffis, T. \& Rohen, M. (2010) "European eParticipation Developments", JeDEM, Vol. 2, No. 2, pp. 89-98.

[17] Daventry District Council (2009) Report on Engagement of the Public in Budget Setting \& Service Planning, Daventry District Council: England.

[18] Davies, J. (2012) "Supporting Open Data through use through active engagement", Position paper from Workshop on using Open Data(W3C), June 2012, Brussels.

[19] De Cindio, F. (2012) "Guidelines for Designing Deliberative Digital Habitats: Learning from e-Participation for Open Data Initiatives", The Journal of Community Informatics, Vol. 8, No. 2. Available from: http://cijournal.net/index.php/ciej/article/view/918/910

[20] Delli Carpini, M. X. (2000) "Youth, Civic Engagement, and the New Information Environment", Political Communication, Vol. 17, No. 4, pp. 341-349.

[21] Dijk, J.A.G.M. (1999) “The One-dimensional Network Society of Manuel Castells”, New media and society, Vol. 1 , No. 1, pp. 127-138.

[22] Dijk, J.A.G.M. (2000) "Models of Democracy and Concepts of Communication" in Hacker, K. L. \& van Dijk, J. A. G. M. (Eds), Digital Democracy: Issues of Theory and Practice, Sage Publications: London.

[23] DiMaggio, P.D.M., Hargittai, E., Russell Neuman, W., Robinson, J. P., (2001) "Social Implications of the Internet", Annual Review of Sociology, Vol. 27, pp. 307-336.

[24] EACEA (2013) Youth Participation in Democratic Life, Final Report, LSE Entreprise, LSE: London.

[25] Fraser, C., Liota, N., Lippa, B., Mach, M., Macintosh, A., Marzano, F., Mentzas, G., Rosendahl, A., Sabol, T., Tambouris, K., Tarabanis, A., Thorleifsdottir, Westhoml, H., Wimmer, M. (2006) "DEMO-net: Deliverable 5.1", Report on current ICTs to enable Participation. DEMO-net. Available from: 
http://www.academia.edu/2737661/DEMO_net_Deliverable_5.1_Report_on_current_ICTs_to_enable_Particip ation?login=olga.marinea@gmail.com\&email_was_taken=true

[26] Fuchs, C. (2008) Internet and Society: Social Theory in the Information Age, New York: Routledge.

[27] Gadras, S. \& Greffet, F. (2013) "Guest Editorial: Towards a comprehensive approach of online political participation", International Journal of Electronic Governance, Vol. 6, No. 4, pp. 258-269.

[28] Gatautis, R. (2010) "Creating Public Value through eParticipation: Wave Project", Economics and Management, Vol. 15, pp. 483-490.

[29] Glencross, A. (2009) "eParticipation in the Legislative Process: Procedural and Technological Lessons from Estonia", JEDEM, Vol. 1, №. 1, pp. 21-29.

[30] Habermas, J. (1996) Between Facts and Norms Contributions to a Discourse Theory of Law and Democracy, MIT Press: Massachusetts Institute of Technology.

[31] Hao, F. (2014) "Towards Next Generation's eVoting", European Research Council. Available from: http://erc.europa.eu/erc-stories/towards-next-generation-e-voting

[32] Hietanen, A. (2012) "eLaw and Free Access to Legislation in Finland and in Europe", Presentation made by the Finnish Ministry of Justice, at the IFLA Conference, 14 August, Helsinki.

[33] Hirschman, A. O. (1994) "Excerpt from Chapter Eight Exit, Voice and Loyalty: Responses to Decline in Firms, Organizations and States", The Social Contract, pp. 272-275.

[34] Howes, D. (2001) "elegislation: Law Making in the Digital Age", McGilL Law Journal, Vol. 47, pp. 39-57.

[35] IDEA (2011) Introducing Electronic Voting: Essential Considerations [Policy Paper], International Institute for Democracy and Electoral Assistance, Sweden: Stockholm.

[36] Involve (2005) People and participation: How to put citizens at the heart of decision-making, Involve \& Together We Can, London.

[37] Jenkins, H. Clinton, Purushotma, R., Weigel, M., Robison, A. J.,Clinton, K. (2006) Confronting the Challenges of Participatory Culture Media Education for the 21st Century, The MIT Press: Massachusetts.

[38] Jochum, V., Pratten, J., Wilding, K. (2005) Civil renewal and active citizenship a guide to the debate, National Council for Voluntary Organisations: London.

[39] Jorgensen, N. (2005) "Design in eGovernment curricula: Bottom-up vs. top-down", in the proceedings of the 2nd Scandinavian eGovernment Workshop, February 2005, Denmark.

[40] Lacigova, O., Maizite, A., Cave, B. (2012) "eParticipation and Social Media: a Symbiotic Relationship?", European Journal of ePractice, No 16.

[41] Livingstone, S. (2010) "Interactivity and participation on the Internet: young people's response to the civic sphere" in Dahlgren, P. (Ed.), Young citizens and new media: learning for democratic participation, Routledge: London, pp. 103-124.

[42] Lowry, P. B., Albrecht, C. C., Nunamaker Jr., J. F., Lee, J. D. (2002) "Evolutionary development and research on Internet-based collaborative writing tools and processes to enhance eWriting in an eGovernment setting", Decision Support Systems, Vol. 34, pp. 229-252.

[43] Lourenco, R. P. \& Costa, J. P. (2006) "Discursive e-Democracy Support", in the proceedings of the 39th Hawaii International Conference on System Sciences, Hawaii.

[44] Luehrs, R. (2009) "Participatory Budgeting in Germany", October, 20th, Pan-European eParticipation Network. Available from: http://pep-net.eu/blog/2009/10/20/e-participatory-budgeting-in-germany/

[45] Lukka, L. (2010) Participatory City Website Development, eParticipation.eu [Online]. Available from: http://eparticipation.eu/2013/08/participatory-city-website-development/

[46] Macintosh, A. (2004) "Characterizing eParticipation in Policy-Making" in the proceedings of the 37th Hawaii International Conference on System Sciences, Hawaii.

[47] Macintosh, A., Coleman, S., \& Lalljee, M. (2005) "eMethods for Public Engagement: Helping Local Authorities communicate with citizens", Bristol City Council for The Local eDemocracy National Project, Bristol. 
[48] Macintosh, A., Robson, E., Smith, E. \& Whyte, A. (2003) "Electronic Democracy and Young People", Social Science Computer Review, Vol. 21, No. 1, pp. 43-54.

[49] Macintosh, A. \& Whyte, A. (2008) "Towards an evaluation framework for eParticipation. Transforming Government: People", Process \& Policy, Vol. 2, No. 1. pp. 16-30.

[50] Maier-Rabler, U. \& Huber, S. (2010) "Sustainable E-Participation through participatory experiences in education Participatory Culture, Political Education, ICTs, and New Media Literacy", Journal of Democracy, Vol. 2, No. 2, pp. 131-144.

[51] Maier-Rabler, U. \& Neumayer, C. (2008) "Youth and eParticipation: Strategies for Innovative Democracy" in the proceedings of EDem 2008 eDemocracy Conference, 29-30 September, Krems, pp. 239-250.

[52] Marcheva, M. (2010) "The Real Political Power of the Internet: Facebook, a Possible New Hub of European Elections?", Paper at the Symposium International, 18-21 March, Luxembourg, International Political Science Association (IPSA).

[53] Medimorec, D., Parycek, P. \& Schossböck (2011) "Vitalizing Democracy through eParticipation and Open Government: An Austrian and Eastern European Perspective", Bertelsmann Stiftung: Gütersloh.

[54] Norris, P. (2004) "eCampaigning and eDemocracy", Paper for the conference on Political Communications in the 21st Century, January 2004, St. Margaret's College, University of Otago, New Zealand.

[55] Norris, P. (2002) "eVoting as the Magic Ballot?" KSG Faculty Research Working Papers Series RWP02-016, April 2002.

[56] NDI: National Democratic Institute (2014) Re-evaluation of the Use of Electronic Voting in the Netherlands. Available from:

[57] https://www.ndi.org/e-voting-guide/examples/re-evaluation-of-e-voting-netherlands

[58] NDI: National Democratic Institute (2014a) The Constitutionality of Electronic Voting in Germany. Available from: https://www.ndi.org/e-voting-guide/examples/constitutionality-of-electronic-voting-germany

[59] OECD (2001) "Citizens as Partners in Policy-Making", Focus Public Management Newsletter, September Issue, No. 21.

[60] OECD (2003) Promise and Problems of eDemocracy: Challenges of Online Citizen Engagement [Report], Organisation for Economic Cooperation and Development, Paris.

[61] Ona, S. (2013) "Exploring the use of new technologies in participation practices in legislation", Journal of eGovernance, Vol. 36, pp. 79-91.

[62] O'Reilly, T. (2005) "What is Web 2.0: Design Patterns and Business Models for the Next Generation of Software", September 9th, O'Reilly Media. Available from: http://www.oreilly.com/pub/a/web2/archive/what-isweb-20.html

[63] Panopoulou, E., Tambouris, E. \& Tarabanis, K. (2009) "eParticipation initiatives: How is Europe progressing?", European Journal of ePractice, No 7, pp. 15-26.

[64] Peixoto, T. (2009) "Beyond Theory: eParticipatory Budgeting and its Promises for eParticipation", European Journal of ePractice, No 7, pp. 55-63.

[65] Porwol, L., Ojo, A., Breslin, J. (2013) "On the Duality of E-Participation - Towards a Foundation for Citizen-Led Participation", Technology-Enabled Innovation for Democracy, Government and Governance, Lecture Notes in Computer Science, Vol. 8061, pp. 211-225.

[66] Putnam,R. D. (2000) Bowling Alone: The Collapse and Revival of American Community, Simon and Schuster: New York.

[67] Riehm, U., Böhle, K. Lindner, R. (2011) "Electronic Petitioning and Modernisation of Petitioning Systems in Europe", Books on Demand: Norderstedt.

[68] Rogers, E. M. (1995) Diffusion of Innovations, The Free Press: New York.

[69] Rosanvallon, P. (2008) "Counter-Democracy. Politics in an Age of Distrust", Cambridge University Press: Cambridge. 
[70] Rosling, H., (2006) “The best Stats you've ever seen”, TED Talk [Video], TED. Available from:

[71] https://www.ted.com/talks/hans_rosling_shows_the_best_stats_you_ve_ever_seen

[72] Sæbø, Ø., Rose, J., Flak, L. S. (2008) "The shape of eParticipation: Characterizing an emerging research area", Government Information Quarterly, Vol. 25, pp. 400-428.

[73] SALAR: Swedish Association of Local Authorities and Regions (2010) "ePetition", Factsheet: The 'Citizen Dialogue' Project, May Issue, No. 7.

[74] Schmitter, P. C. \& Trechsel, A. H. (2004) "The Future of Democracy in Europe Trends, Analyses and Reforms", A Green Paper for the Council of Europe, Council of Europe Publishing: Strasbourg.

[75] Shah, A. (2007) Public Sector Governance and Accountability Series: Participatory Budgeting, The World Bank: Washington, DC.

[76] Smith, S. \& Dalakiouridou, E. (2009) "Contextualising Public (e)Participation in the Governance of the European Union", European Journal of ePractice, No 7, pp. 4-14.

[77] Stanley, J. W. \& Weare, C. (2004) "The Effects of Internet Use on Political Participation", Administration \& Society, Vol. 36, No. 5, pp. 503-527.

[78] Strandberg, K. (2013) "A social media revolution or just a case of history repeating itself? The use of social media in the 2011 Finnish parliamentary elections", New Media \& Society, Vol. 15, No. 8, pp. 1329-1347.

[79] Tomkova, J. (2009) "eConsultations: New tools for civic engagement or facades for political correctness?", European Journal of ePractice, No 7, pp. 45-54.

[80] Trafficestimate (2015) Eur-lex.europa.eu Traffic Estimate [Online] Available from: http://www.trafficestimate.com/eur-lex.europa.eu

[81] UN Women (2012) What is eCampaigning, United Nations Entity for Gender Equality and the Empowerment of Women. Available from: http://www.endvawnow.org/en/articles/1271-what-is-ecampaigning.html?next=1272

[82] Vesnic-Alujevic, L. (2011) "Communicating with voters by blogs? Campaigning for the 2009 European Parliament elections", Discourse \& Communication, VoL. 5, No. 4, pp. 413-428.

[83] West, D. M. (2004) "eGovernment and the Transformation of Service Delivery and Citizen Attitudes", Public Administration Review, Vol. 64, No. 1.

[84] Xifra, J. (2011) "Americanization, Globalization, or Modernization of Electoral Campaigns? Testing the Situation in Spain", American Behavioral Scientist, Vol. 55, №. 5, pp. 667-682.

[85] Zissis, D., Lekkas, D., \& Papadopoulou, A.E. (2009) "Competent Electronic Participation Channels in Electronic Democracy", Electronic Journal of eGovernment, Vol. 7, Issue 2, pp. 195-208. 